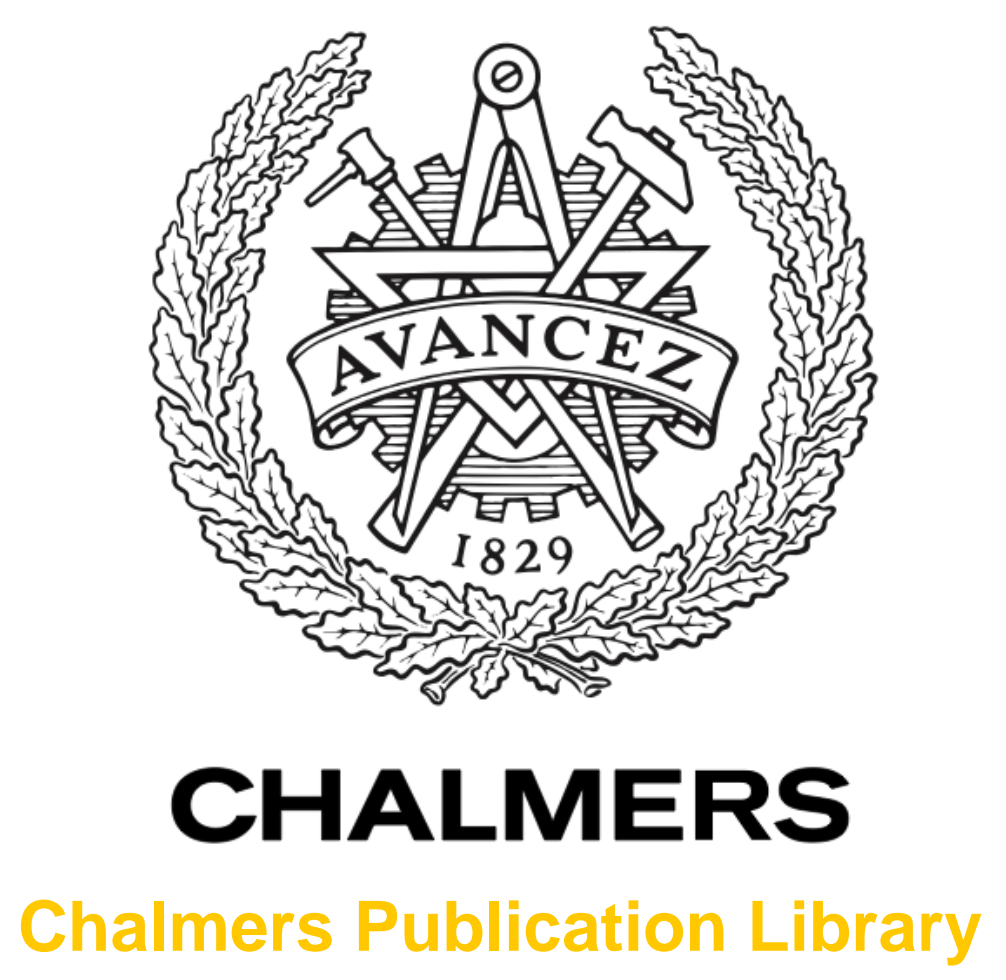

\title{
Analysis of Mechanical Behavior of Corroded Reinforced Concrete Structures
}

This document has been downloaded from Chalmers Publication Library (CPL). It is the author's version of a work that was accepted for publication in:

ACI Structural Journal (ISSN: 0889-3241)

Citation for the published paper:

Zandi Hanjari, K. ; Kettil, P. ; Lundgren, K. (2011) "Analysis of Mechanical Behavior of

Corroded Reinforced Concrete Structures". ACI Structural Journal, vol. 108(5), pp. 532-541.

Downloaded from: http://publications.lib.chalmers.se/publication/145262

Notice: Changes introduced as a result of publishing processes such as copy-editing and formatting may not be reflected in this document. For a definitive version of this work, please refer to the published source. Please note that access to the published version might require a subscription. 


\title{
Analysis of Mechanical Behavior of Corroded Reinforced Concrete Structures
}

\author{
by Kamyab Zandi Hanjari, Per Kettil, and Karin Lundgren
}

\begin{abstract}
This paper presents a methodology to analyze the mechanical behavior and remaining load-carrying capacity of corroded reinforced concrete $(R C)$ structures. The methodology is used to predict the mechanical behavior for a structure with an observed amount of uniform and pitting corrosion at a given time. The effect of corrosion is modeled as a change in geometry and properties of corroded reinforcement and surrounding concrete-that is, a reduction of steel area and ductility, removal of spalled concrete, modification of concrete response due to corrosion cracks, and modification of bond-slip properties. The methodology is applied to concrete beams affected by reinforcement corrosion, using both finite element analyses and analytical methods. A comparison of the results with available experiments from the literature indicated that the changes in failure mode and failure load caused by uniform and pitting corrosion of reinforcement can be predicted reasonably well by using the proposed methodology.
\end{abstract}

Keywords: bond properties; corrosion of reinforcement; existing concrete structures; load-carrying capacity; material properties.

\section{INTRODUCTION}

There is a growing need for reliable methods to predict the load-carrying capacity and remaining service life of deteriorated reinforced concrete (RC) structures as a decision basis for optimized maintenance and repair strategies. ${ }^{1,2}$ In an ongoing research project, the load-carrying capacity of deteriorated RC structures is studied. The part of the project presented herein is focused on deterioration due to the corrosion of reinforcement.

The corrosion of steel reinforcement is one of the most common causes of deterioration of RC. The corrosion process transforms steel into rust, leading to 1) an area reduction of the reinforcement bars; and 2) volume expansion that generates splitting stresses in the concrete, which may crack and spall the concrete cover and affect the bond between the reinforcement and the concrete. ${ }^{3-6}$

Previous research has been mainly concerned with the causes and mechanisms of reinforcement corrosion and the local effects on bond around a single reinforcement bar. ${ }^{7,8}$ Relatively little attention has been devoted to the practically important problem of assessing the residual load-carrying capacity of corroded concrete structures, however; this has been studied by few researchers. ${ }^{4,9,10}$ The aim of this study is to present a methodology to analyze the mechanical behavior and remaining load-carrying capacity of corroded RC structures. The effect of corrosion is modeled as a change in geometry and properties - that is, the reduction of steel area, removal of spalled concrete, and modification of bond-slip properties. The modification of bond-slip properties is based on previous research, where a detailed three-dimensional (3-D) solid finite element (FE) model has been developed and used to determine the one-dimensional (1-D) bond-slip response for corroded reinforcement. ${ }^{11-14}$ The methodology is intended for use at different approximation levels-for example, from full 3-D solid models, intermediate shell and frame models, and beam models to analytical calculations, depending on the means available and requirements of the results. In this study, the methodology is applied in twodimensional (2-D) FE analysis and analytical calculation of the residual capacity of corroded RC beams.

\section{RESEARCH SIGNIFICANCE}

This paper presents a methodology to evaluate the mechanical behavior of corroded RC structures. The principle of the methodology is that the effect of damage can be modeled by adapting material properties and modifying the bond properties and geometry. Suggestions for adjusting the material properties of corroded reinforcement and concrete given by other researchers were gathered and put into a framework.

One important feature of the work is the application of a simple analytical model to predict the bond-slip behavior of corroded bars, which is used as input in structural analysis to assess existing structures. Another feature of the work is the effort made to show the effect of pitting corrosion on the capacity of corroded beams; a method to include this effect in an FE model is also suggested in this paper.

\section{METHODOLOGY FOR ANALYZING MECHANICAL BEHAVIOR OF CORRODED RC}

In the following, a methodology to analyze the mechanical behavior and remaining load-carrying capacity of corroded $\mathrm{RC}$ structures is proposed. The methodology is based on the premise that the methods of structural analysis in use for concrete structures should be applied to the corroded RC structure. It is assumed that the effect of corrosion can be modeled as a change in geometry and material properties of the concrete, the reinforcement, and the interface:

1. Concrete: (a) removal of spalled concrete by changing the concrete geometry; and (b) modification of the properties of the cracked concrete around the corroded reinforcement.

2. Corroded longitudinal reinforcement and stirrup (uniform and/or pitting corrosion): (a) change of reinforcement area; and (b) change of reinforcement ductility.

3. Reinforcement/concrete interface: modification of bond properties.

\section{Concrete}

The corrosion process transforms steel into rust, leading to volume expansion that generates splitting stresses in the

ACI Structural Journal, V. 108, No. 5, September-October 2011.

MS No. S-2008-295.R3 received August 5, 2010, and reviewed under Institute publication policies. Copyright (C) 2011, American Concrete Institute. All rights reserved, including the making of copies unless permission is obtained from the reserved, including the making of copies unless permission is obtained from the published in the July-August 2012 ACI Structural Journal if the discussion is received by March 1, 2012 . 
$\overline{A C I}$ member Kamyab Zandi Hanjari is a Researcher at Chalmers University of Technology, Gothenburg, Sweden. He received his BSc in civil engineering from Iran University of Science and Technology, Tehran, Iran, in 2004, and his MSc in structural engineering and PhD in concrete structures from Chalmers University of Technology in 2006 and 2010, respectively. He was awarded second place in the 2004 ACI Concrete Projects Competition. His research interests include structural analyses of deteriorated reinforced concrete structures, especially bridges.

Per Kettil is a Consulting Bridge Engineer and an Associate Professor at Chalmers University of Technology. He received his MSc in civil engineering and his PhD in structural mechanics from Chalmers University of Technology in 1995 and 2001, respectively. His research interests include computer-based methods for structural analyses and design of bridges.

Karin Lundgren is an Associate Professor at Chalmers University of Technology. She received her MSc in civil engineering and her $P h D$ in concrete structures from Chalmers University of Technology in 1991 and 1999, respectively. Her research interests include complete buildings to material level within the field of concrete structures and combining modeling and experimental work, with special expertise in the structural effects of deterioration.

concrete. These stresses may cause the surrounding concrete to crack. In regions with low levels of confinement, the concrete cracks and the concrete cover spalls off, whereas in regions with high levels of confinement, the concrete cracks and the uncracked parts in between the cracks contributes to the stiffness and load-carrying capacity.

It is clear that the change in concrete geometry affects the stiffness and strength of the structure and must be taken into account. The extent and depth of the spalled areas should be measured and documented. The geometry used in the analysis should then be modified accordingly. In regions with high confinement, cracked concrete under compression exhibits lower strength and stiffness than virgin concrete, and the compression-softening effect is related to the degree of transverse cracking and straining present, ${ }^{15}$ as illustrated in Fig. 1. This significantly influences the strength, ductility, and load-deformation response of a concrete element. The reduced concrete strength can be calculated by using the following equations ${ }^{4}$

$$
\begin{gathered}
f_{c c, \text { cracked }}=\frac{f_{c c}}{1+k \frac{\varepsilon_{1}}{\varepsilon_{c c o}}} \\
\varepsilon_{1}=\left(n w_{c r}\right) / b_{0}
\end{gathered}
$$

where $w_{c r}$ can be estimated by ${ }^{16}$

$$
w_{c r}=\sum u_{i, c o r}=2 \pi\left(v_{r s}-1\right) x
$$

where $f_{c c}$ is the compressive strength of virgin concrete; $k$ is a coefficient related to bar roughness and diameter $(k=0.1$ for medium-diameter ribbed bars $\left.{ }^{17}\right) ; \varepsilon_{c c o}$ is strain at the peak compressive strength $f_{c c} ; \varepsilon_{1}$ is average tensile strain in the cracked concrete perpendicular to the direction of the applied compression; $b_{0}$ is the undamaged beam section width; $n$ is the number of reinforcement bars in the compression zone; $w_{c r}$ is the crack width for a given corrosion penetration $x$; $u_{i, c o r}$ is the opening of each single corrosion crack; and $v_{r s}$ is the ratio of volumetric expansion of the oxides with respect to the virgin material.

The expansion of the iron depends on the level of oxidation. ${ }^{18}$ The ratios of volumetric expansion of different typical oxides with respect to the virgin material given in the literature ${ }^{19}$ varies between $v_{r s}=1.7$ for $\mathrm{FeO}$ and $v_{r s}=6.15$ for $\mathrm{Fe}(\mathrm{OH})_{3} 3 \mathrm{H}_{2} \mathrm{O}$. While the value of $v_{r s}=2.0$ suggested by Molina et al. ${ }^{16}$ is frequently used in numerical analysis of corroded concrete, ${ }^{4,8,11-14}$ Bhargava et al. ${ }^{20}$ proposed a value of $v_{r s}=3.39357$ based on the available published experimental data. In this study, the value of $v_{r s}=2.0$ was chosen for all the analyses, except for one analysis in which two values - that is, $v_{r s}=2.0$ and 3.4-are used for comparison.

Cracked concrete around corroded stirrups influences the shear capacity of a beam. If the concrete in this region has been cracked due to corrosion, it has reached the maximum tensile strength of concrete. Thus, any further tensile stress induced by mechanical loading will contribute towards a larger crack opening. Hence, the behavior of concrete around corroded stirrups can be simulated by adopting a lower tensile strength, as illustrated in Fig. 1. Here, a simplifying assumption was used to reduce the tensile strength proportionally to the reduction in compressive strength

$$
f_{c t, \text { cracked }}=\frac{f_{c c, \text { cracked }}}{f_{c c}} f_{c t}
$$

where $f_{c t}$ is the tensile strength of virgin concrete.

\section{Uniformly corroded reinforcement}

The reduction of the effective reinforcement area, or diameter, is the most evident effect to take into account for uniform corrosion. This is done as follows

$$
\phi=\phi_{0}-2 x
$$

where $\phi$ is the remaining effective diameter of the reinforcement; $\phi_{0}$ is the original diameter; and $x$ is the corrosion (rust) penetration.

The reduction of the reinforcement diameter is most accurately obtained by direct measurements. On a corroded

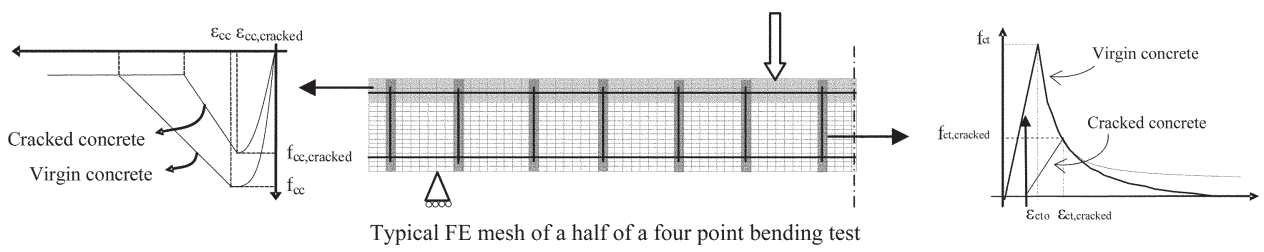

Fig. 1-Schematic illustration of methodology applied on typical FE model. 
structure, parts of the concrete cover might have spalled off, and the remaining bar diameter could then be measured on the exposed bars after removal of the rust layer. For less corroded structures where the cover has not yet spalled off, small parts of the cover could be removed at noncritical locations and afterwards repaired. An alternative to direct measurements is to calculate an estimation of the corrosion penetration based on the corrosion rate and time of corrosion initiation. The reinforcement in the analysis model should then be modified accordingly.

Several studies investigated the effect of uniform corrosion on the mechanical properties of reinforcement. The strength ratio and elastic modulus of reinforcement are not significantly affected by uniform corrosion, and consequently the corresponding values for noncorroded reinforcement can be adopted. ${ }^{21}$ The level of reinforcement corrosion does not influence the tensile strength of reinforcement, calculated on the actual area of cross section, ${ }^{21-23}$ while the ultimate strain is significantly reduced by uniform corrosion. Although the measured ultimate strain of corroded smaller-diameter reinforcement was generally smaller than those of corroded larger bar diameter, the observed differences were not greater than 5\%. Hence, the reduction of ductility of corroded reinforcement is primarily a function of the amount of corrosion rather than of the bar type and diameter. ${ }^{21}$

Practical models for the residual ductility of corroded reinforcement are confined to empirical correlations with a cross-sectional loss of the corroded reinforcement. Such relationships have been presented in different forms, such as Eq. $(6)^{23}$

$$
\varepsilon_{s u}=\left(1-\alpha_{1} A_{c o r}\right) \varepsilon_{s u 0}
$$

where esu is the ultimate strain of corroded reinforcement, with the average cross-sectional loss of $A_{c o r}$ expressed as a percentage of the original cross section; $\varepsilon_{s u 0}$ represents the ultimate strain of noncorroded reinforcement; and $\alpha_{1}$ is an empirical coefficient.

Depending on different exposure environments, carbonation, or chlorides, the reported al coefficient varies from 0 to 0.06 . An $\alpha_{1}$ coefficient of 0.01 corresponds to a situation when the reduction in ductility is proportional to the average crosssectional loss. A summary of the $\alpha_{1}$ coefficient determined from various experimental investigations is available in the literature. $^{23,24}$

\section{Pitting corrosion of reinforcement}

The residual cross-sectional area of locally corroded reinforcement was first estimated with the experimentally verified assumption that the maximum penetration of pitting corrosion is approximately four to eight times the average corrosion penetration of uniform corrosion. ${ }^{25}$ Measurements on relatively lightly corroded reinforcement ${ }^{23}$ showed that the breadth of pits averaged slightly less than twice the depth, confirming the assumption of the circular cross section of pits. Based on this assumption, the cross-sectional loss at a pit increases approximately in proportion to the square of its depth. In this study, the pit configuration proposed by Val and Melchers ${ }^{26}$ is used to calculate the residual area of locally corroded reinforcement.

The notch effect in a locally corroded reinforcement induces large and localized strain in the bar. Because the length of the bar affected by pitting corrosion is short, approximately two times the bar diameter in total, ${ }^{27}$ the average strain of the bar is smaller than the local strain at the pit. Hence, the bar fails at an average strain smaller than the ultimate strain of the noncorroded $\mathrm{bar}^{4,21}$ and the average ductility of the bar is impaired. Very brittle behavior is expected when $50 \%$ of the cross section of the reinforcement is locally corroded. ${ }^{28}$ The ultimate strain of locally corroded reinforcement reduces much more significantly than the yield and ultimate strengths. ${ }^{21,27,29}$ In practice, the effect of pitting corrosion on the ductility of reinforcement can also be treated similarly to uniform corrosion, using Eq. (6) and choosing a correct value of the $\alpha_{1}$ coefficient.

\section{Reinforcement-concrete interface}

The splitting stresses in the corroded concrete may crack and spall the concrete cover and affect the bond-slip between the reinforcement and the concrete. In severe cases, this could lead to a brittle collapse of the structure, and hence the change in bond properties must be taken into account in the analysis.

Areas with spalled-off concrete covers and the corrosion penetration of corroded bars should be measured and documented, as stated previously. In addition, crack patterns that indicate splitting of the cover should be measured and documented. The bond properties of the analysis model should then be modified accordingly. The modification could be made using the method proposed in Lundgren et al. ${ }^{30}$ The method is based on research presented in the literature ${ }^{11-13}$ and the 1-D bond-slip model of CEB-FIP Model Code 1990. ${ }^{31}$ A brief description of the method is given in the following section. This procedure can be applied to solid and structural analysis models where the bond-slip between the concrete and reinforcement is modeled by 1-D bond-slip interface elements, such as in the analyses presented in this paper. For simpler structural analysis models where the bond-slip is not directly incorporated in the model, it is proposed that the procedure described $^{30}$ can be applied to calculate anchorage length. Either the capacity of the reinforcement is then adjusted in the anchorage region or the anchorage is checked manually.

\section{Modification of bond-slip behavior}

In locations where the concrete cover has completely spalled off, the assumption is made that the bond strength is zero. In other areas where the cover still remains (but may be cracked), the bond-slip properties could be based on the following:

1. The bond strength $\tau_{b}$ versus slip $s$, curves, and parameters of CEB-FIP Model Code 199031 are adopted for the uncorroded case. To account for intermediate cases in between the extreme cases "confined" (that is, ductile pullout failure) and "unconfined" (that is, brittle failure due to cover cracking induced by the radial tensile stress), the following interpolation formula is proposed. ${ }^{30}$

$$
\tau_{b}=k_{\text {uncor }} \tau_{b, \text { conf }}+\left(1-k_{\text {uncor }}\right) \tau_{b, \text { unconf }}
$$

The interpolation factor is determined by

$$
k_{\text {uncor }}=\max \left\{\begin{array}{l}
k_{c / \phi} \\
k_{\text {Asw }}
\end{array}\right.
$$

where $k_{c / \phi}$ is a factor that depends on the ratio of cover to bar diameter $c / \phi$; and $k_{A s w}$ is a factor that depends on the amount 
of effective transverse reinforcement $A_{s w} / s$, according to Fig. 2(a).

2. The effect of corrosion is taken into account by adjusting the CEB-FIP Model Code 199031 bond-slip curves as follows:

(a) The amount of transverse reinforcement $A_{s w} / s$ is reduced due to corrosion of the transverse reinforcement;

(b) The bond-slip curve of the corroded bar is obtained by shifting (moving) the curve for the uncorroded bar along the slip axis by the distance

$$
\Delta s=a x
$$

where $a$ is assumed to be a constant; and $x$ is the corrosion penetration. This was suggested by Schlune $^{13}$ (refer also to Lundgren et al. ${ }^{14}$ The constant $a$ was found to be approximately 8.1 for the analyzed cases; this is used in the analyses described in this paper.

(c) To account for the possible change in the failure mode due to corrosion from pullout to splitting failure, the parameters for the bond-slip curve in the corroded case are obtained by interpolation of the parameters of the uncorroded case.

$$
\tau_{b}=k_{c o r} \tau_{b, \text { conf }}+\left(1-k_{c o r}\right) \tau_{b, \text { unconf }}
$$

The factor kcor depends on the ratio $x / x_{c r}$, where $x_{c r}$ is the corrosion level that cracks the cover (Fig. 2(b)). The corrosion penetration that causes cover cracking has been found by curve fitting to analysis results from the detailed 3 -D model, ${ }^{12}$ as given by the following formula

$$
\begin{gathered}
x_{c r}=11\left(\frac{f_{c c}}{40}\right)^{0.8}\left(\frac{c}{\phi}\right)^{1.5}\left(\frac{\phi}{16}\right)^{0.5}(\mu \mathrm{m}) \\
x_{c r}=4.073 \times 10^{-5} \cdot\left(\frac{f_{c c}}{40}\right)^{0.8}\left(\frac{c}{\phi}\right)^{1.5}\left(\frac{\phi}{16}\right)^{0.5}
\end{gathered}
$$

where $x_{c r}$ is the corrosion level that cracks the cover in $\mathrm{mm}$ (in.); $f_{c c}$ is the concrete compressive strength in MPa (psi); $c$ is the concrete cover in $\mathrm{mm}$ (in.); and $\varnothing$ is the reinforcement bar diameter in $\mathrm{mm}$ (in.). In regions where cover cracking has been observed in the structure, the ratio $x / x_{c r}$ should be set to 1 .

\section{ANALYSES OF BEAMS WITH ANCHORAGE FAILURE TESTED BY CORONELLI' ${ }^{32}$}

The proposed methodology was applied to analyze the load-carrying capacity of beam tests where pullout failure was limiting. Nonlinear FE analyses were performed to model the beam tests and the results were compared with the experiments.

\section{Experimental setup}

Coronelli ${ }^{32}$ tested the bond-slip behavior of uncorroded and corroded reinforcement by using a four-point bending test on a beam with a hinge arrangement in the middle to

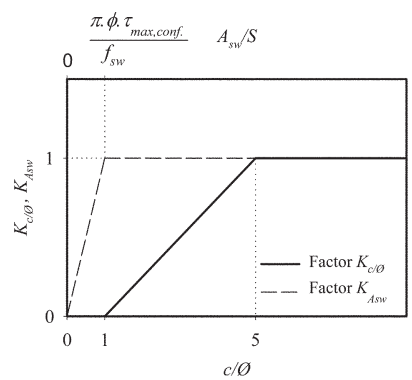

(a)

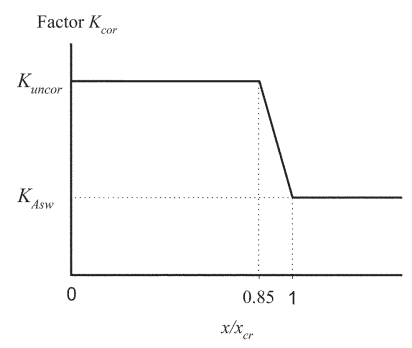

(b)
Fig. 2-(a) Interpolation factor $^{30}$; and (b) failure mode factors. ${ }^{30}$

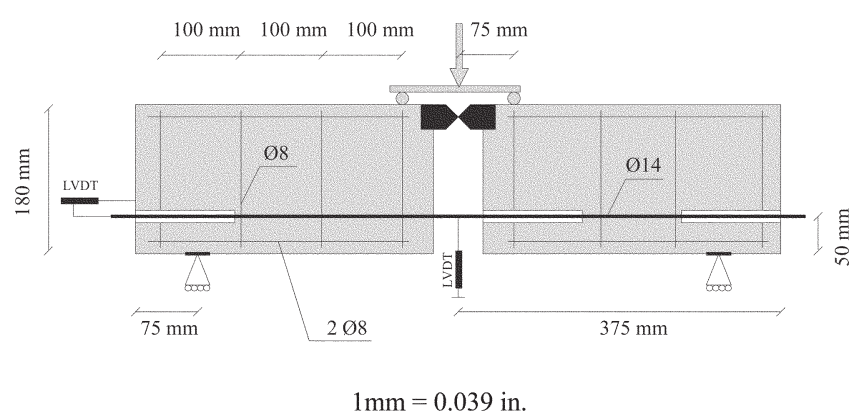

Fig. 3-Test setup of beams tested by Coronelli. ${ }^{32}$

give a well-defined force in the reinforcement bar (Fig. 3). In addition, the bar was only bonded to the concrete over a short length to get a rather uniform bond stress. During the tests, the load, the midspan deflection of the beam, and the slip at the passive ends of the reinforcing bar were measured. Test results were reported for $0,1.2,2.4$, and $4.8 \%$ corrosion, corresponding to $0,50,100$, and $150 \mu \mathrm{m}$ corrosion penetration on the tested $\phi 14$ bar; the stirrups were not corroded. More details of the beam tests are given by Coronelli. $^{32}$

\section{FE analysis}

Following the suggested methodology, the effect of reinforcement corrosion was modeled as a change of reinforcement diameter and by modifying the bond-slip properties according to the methodology. The effect of corrosion on the ductility of the reinforcement and the cracking of concrete around the corroded reinforcement bars were not considered, being of minor importance as all the beams failed due to anchorage.

The beam was modeled in 2-D and, due to symmetry, only half of the beam was modeled. The dimensions, reinforcement, support conditions, and loading arrangement are shown in Fig. 3. In the tests, steel plates and roller bearings were used at the supports. In the FE model, the steel plate was modeled as infinitely stiff by constraint equations. The FE nodes along the plate were tied to the center node, thus forcing the nodes to remain in a straight line but allowing for rotation. The center node was supported for displacement in the y-direction. At the symmetry line, the special hinge arrangement in the test was modeled by a steel plate with one node in the middle fixed in the $\mathrm{x}$-direction. The reinforcement bar node was also fixed in the $\mathrm{x}$-direction.

For the concrete, four-node quadrilateral plane stress elements were used. The concrete was modeled with a 


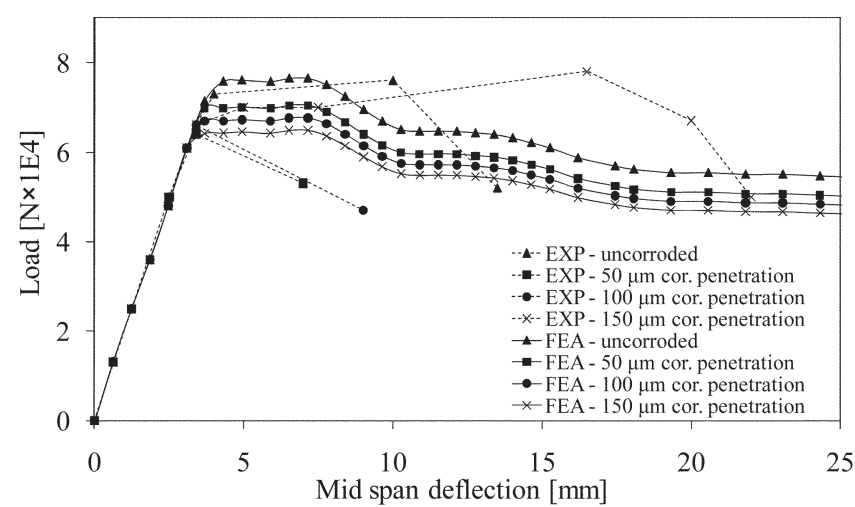

Fig. 4-Load versus displacement for beams tested by Coronelli. ${ }^{32}$ (Note: $1 \mathrm{~mm}=0.039 \mathrm{in}$.; $1 \mathrm{kN}=0.225$ kips.)

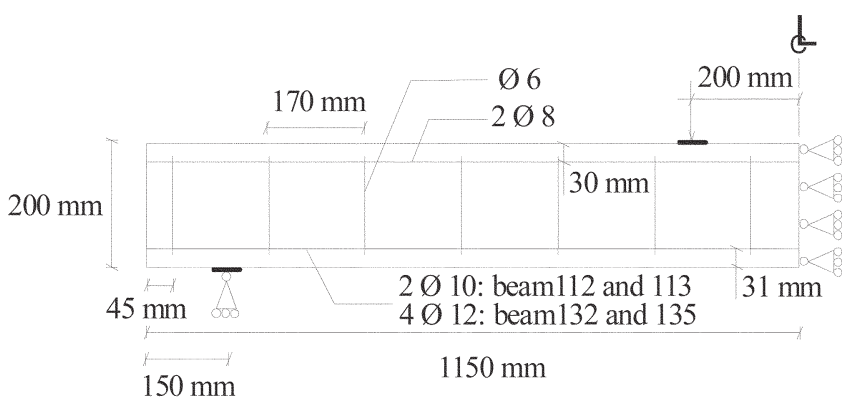

Fig. 5-2-D model of beams tested by Rodriguez et al. ${ }^{1}$ (Note: $1 \mathrm{~mm}=0.039 \mathrm{in}$.)

constitutive model based on nonlinear fracture mechanics using a smeared rotating crack model based on total strain. ${ }^{33}$ The crack band width was assumed to be equal to the element size ( $5 \mathrm{~mm}$ [0.2 in.]). For the tension behavior of concrete, the curve by Hordijk et al. ${ }^{34}$ with $f_{c t}=2.77 \mathrm{MPa}$ (402 psi) was chosen, as described in the literature. ${ }^{33,34}$ For concrete in compression, a simple elastic ideal-plastic behavior with $f_{c c}=36 \mathrm{MPa}$ (5220 psi) was assumed.

The longitudinal reinforcement was modeled by twonode truss elements assuming uniform corrosion. The effective diameter of the bar was adjusted with respect to the corrosion penetration according to the methodology. The interaction between the reinforcement and the concrete was modeled with an interface element with a 1-D bondslip law, as described in the methodology. The stirrups were embedded in the four-node quadrilateral plane stress elements, corresponding to perfect bond between the stirrups and the surrounding concrete. An incremental static analysis was performed using a Newton-Raphson iterative scheme to solve the nonlinear equilibrium equations. In a phased analysis, the self-weight load was applied first. Then, the external load was gradually applied as prescribed displacement at the loading point.

\section{Results and discussion}

Figure 4 shows comparisons between the computed and measured results for the beam tests with different corrosion penetrations. All beams failed due to pullout failure in both experiments and analyses. The initial stiffness for the beams agrees very well for all cases. Also, the maximum load agrees fairly well for all cases, but differences are visible in the post-peak behavior for some of the beams.

It is worth noting that the maximum load decreases from $75 \mathrm{kN}$ (16.9 kips) for the uncorroded beam to $65 \mathrm{kN}$ (14.6 kips) for the beam with $150 \mu \mathrm{m}(0.0059 \mathrm{in}$.) corrosion penetration in both experiments and analyses. This corresponds to a fairly high load capacity of the corroded beam-approximately $87 \%$ of the load capacity of the reference beam. For a rather low amount of corrosion, the radial stresses between the bar and concrete increases due to the increase in the bar diameter. This may lead to a slightly higher load capacity of the corroded beams; however, further corrosion will lead to development of longitudinal cracking and a reduction in load capacity. ${ }^{3}$ This type of behavior is seen in the beam tests but is not included in the 1-D bond-slip law. Therefore, successive deterioration of the load capacity is achieved in the analysis with an increased amount of corrosion attack.

The beam tests also show a rather high residual load capacity after the failure takes place; this agrees very well with what is estimated in the FE analysis. After all, this analysis and the comparison made with the beam tests carried out by Coronelli ${ }^{32}$ are useful, mainly to verify the proposed methodology for the given corrosion levels. Therefore, further verification of the 1-D bond-slip model and the proposed methodology is needed for higher corrosion attacks.

\section{ANALYSES OF BEAMS WITH BENDING AND SHEAR FAILURE TESTED BY RODRIGUEZ ET AL. ${ }^{1}$}

Rodriguez et al. ${ }^{1}$ tested the influence of reinforcement corrosion on RC beams loaded in four-point bending. During the tests, the load and the midspan deflection of the beam were measured. Test results were reported for different beam dimensions and reinforcement arrangements to produce different failure modes, and always for one reference specimen and some corroded specimens with different corrosion levels.

\section{Experimental setup}

Four of the beams with curtailed reinforcement were analyzed using the proposed methodology, both in the FE analysis and with analytical methods. Uncorroded Beam 112 and Corroded Beam 113 with $490 \mu \mathrm{m}$ (0.01911 in.) corrosion penetration were under-reinforced and failed in bending due to yielding of reinforcement. The other two beams had twice as much tensile reinforcement as the first beams; half of the reinforcement was curtailed at a distance $250 \mathrm{~mm}$ (9.75 in.) from the end of the beam (Fig. 5). The noncorroded beam with a high reinforcement amount, Beam 132, failed due to combined bond and shear effects, whereas the corroded one with $430 \mu \mathrm{m}$ (0.01677 in.) corrosion penetration, Beam 135, failed in shear only.

\section{FE analysis}

The corroded beams were modeled considering the effect of reinforcement corrosion by reducing the reinforcement area and ductility, assuming both uniform and pitting corrosion. Also included were the response of cracked concrete around the corroded reinforcement and the modified bond-slip properties according to the methodology. The beams were modeled in 2-D and, due to symmetry, only half of a beam was modeled (Fig. 5). The principal aspects of the FE model and material law for concrete in tension were the same as the model of the beams tested by Coronelli. ${ }^{32}$ The concrete material properties are given in Table 1 . 
Table 1-Concrete material properties used in analyses

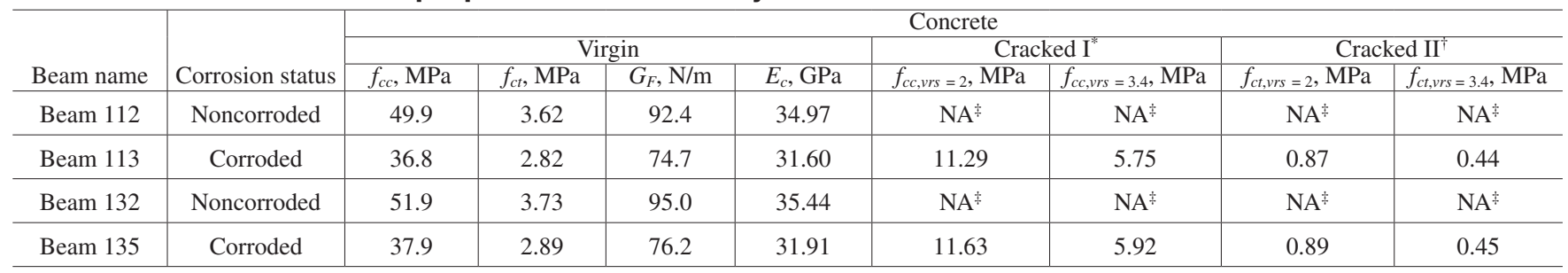

${ }^{*}$ Cracked concrete around corroded compressive reinforcement.

Cracked concrete around corroded strips.

*NA is not available.

Notes: $1 \mathrm{MPa}=145 \mathrm{psi} ; 1 \mathrm{~N} / \mathrm{m}=0.74 \mathrm{ft} \cdot \mathrm{lbf} ; 1 \mathrm{GPa}=145 \mathrm{ksi}$.

Table 2-Residual cross-sectional area of reinforcements

\begin{tabular}{|c|c|c|c|c|c|c|c|}
\hline Beam name & Corrosion status & \multicolumn{2}{|c|}{ Bottom reinforcement } & \multicolumn{2}{|c|}{ Top reinforcement } & \multicolumn{2}{|c|}{ Stirrup } \\
\hline Beam 113 & Uniform corrosion & 9.02 & 63.87 & 6.92 & 37.59 & 5.02 & 19.78 \\
\hline Beam 132 & Noncorroded & 12.0 & 113.04 & 8.0 & 50.24 & 6.0 & 28.26 \\
\hline Beam 135 & Uniform corrosion & 11.14 & 97.42 & 6.92 & 37.59 & 4.94 & 19.16 \\
\hline
\end{tabular}

*NS is not specified.

Note: $1 \mathrm{~mm}=0.039$ in

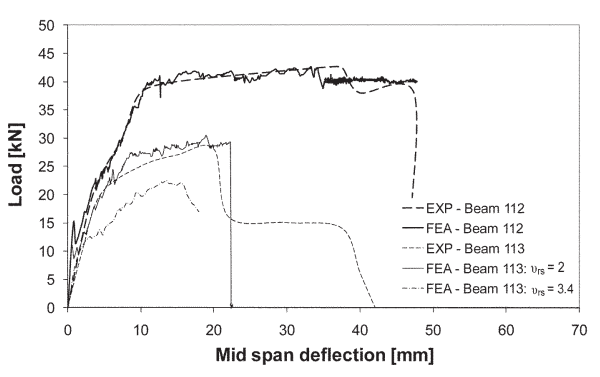

(a)

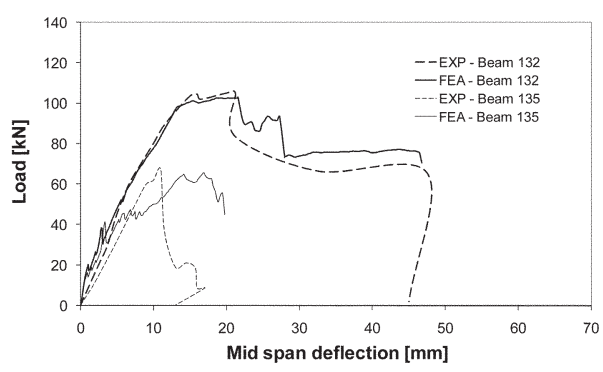

(b)

Fig. 6-Load versus displacement for beams tested by Rodriguez et al. ${ }^{1}$ : (a) Beams 112 and 113; and (b) Beams 132 and 135. (Note: $1 \mathrm{~mm}=0.039$ in.; $1 \mathrm{kN}=0.225$ kips.)

For concrete in compression, to enable a better description of the concrete compression failure mode, it was necessary to include the hardening of concrete in compression and to include a descending branch of the stress-strain curve. Here, the hardening-softening curve in compression according to Thorenfeldt et al..$^{35}$ was applied. When this relationship is used, localization of the deformations in compressive failure needs to be taken into account. Van $\mathrm{Mier}^{36}$ showed that the compression-softening behavior is related to the boundary conditions and the size of the specimen. Consequently, as the Thorenfeldt et al. ${ }^{35}$ compression curve has been defined from measurements in compression tests on $300 \mathrm{~mm}$ (11.7 in.) long cylinders, the softening branch was modified for the concrete element size of $20 \mathrm{~mm}$ (0.78 in.). This was done by assuming that the compressive failure would take place in one element row. This assumption was later verified in the analysis.

The effect of cracking around corroded compressive reinforcement and stirrups was considered using the principles described in the methodology. The crosssectional area of the corroded reinforcements was modified according to the measured residual reinforcing bar diameter (Table 2). The behavior of the reinforcement is defined using a plasticity model based on the yield function of Von Mises. The yield and ultimate values of stresses and strains are inputs to the plasticity model, allowing for further adjustment of the ductility of corroded reinforcement. The ultimate strain of the reinforcement was modified using Eq. (6) with an $\alpha_{1}$ coefficient equal to 0.017 and 0.06 for uniform and pitting corrosion, respectively. The uniformly corroded reinforcing bar exhibited approximately 50\% of the ultimate strain of a noncorroded reinforcing bar. The ultimate stress was assumed to be equal to the yield stress. Pitting spots, assuming to affect a length of stirrup equal to twice the stirrup diameter, ${ }^{27}$ were distributed randomly on the stirrups so that $10 \%$ of the total stirrups' length was affected. This allowed for two spots of pitting corrosion on each stirrup. The place of the pitting corrosion on the stirrup was determined using the random function in MATLAB, generating a uniform distribution of random numbers. The measured pitting corrosion of tensile reinforcements was reported for the midspan, ${ }^{1}$ zone of the constant bending moment; therefore, the reinforcement properties were adapted accordingly. The interaction between the reinforcement and concrete was modeled as described in the methodology. 


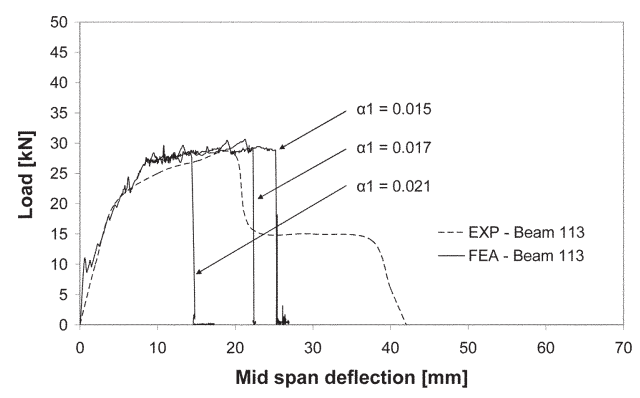

(a)

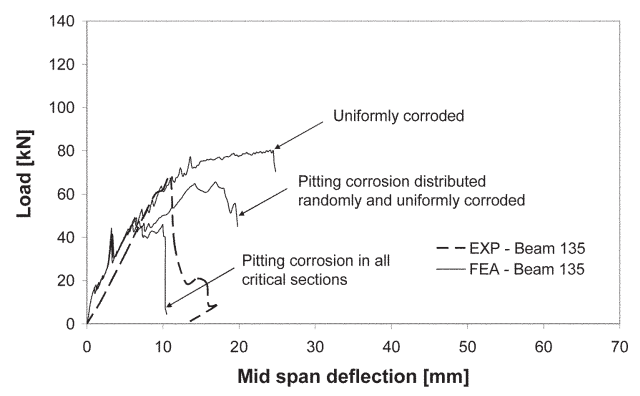

(b)

Fig. 7-Load versus displacement: (a) Corroded Beam 113; and (b) Corroded Beam 135. (Note: $1 \mathrm{~mm}=0.039$ in.; $1 \mathrm{kN}=0.225$ kips.)

Table 3-Six different cross sections used for analytical calculations

\begin{tabular}{|c|c|c|c|c|c|c|}
\hline & 1 & 2 & 3 & 4 & 5 & 6 \\
\hline Cross section & [ & 9 & 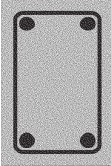 & 6 & {$\left[\begin{array}{ll}9 & 9 \\
& \end{array}\right.$} & 6 \\
\hline $\begin{array}{l}\text { Uniform } \\
\text { corrosion }\end{array}$ & & $\checkmark$ & & $\checkmark$ & $\checkmark$ & $\checkmark$ \\
\hline $\begin{array}{l}\text { Pitting } \\
\text { corrosion }\end{array}$ & & & $\checkmark$ & $\checkmark$ & $\checkmark$ & $\checkmark$ \\
\hline $\begin{array}{l}\text { Spalled top and } \\
\text { bottom cover }\end{array}$ & & & & & $\checkmark$ & $\checkmark$ \\
\hline $\begin{array}{l}\text { Spalled side } \\
\text { cover }\end{array}$ & & & & & & $\checkmark$ \\
\hline
\end{tabular}

\section{Results and discussion of FE analysis}

Comparisons between the numerical and experimental results are presented in Fig. 6. The failure mode was the same as in the experiments for all analyzed beams, as will be discussed in the following. Furthermore, the capacity and stiffness agreed well for all beams.

Noncorroded Beam 112 failed in bending due to yielding of tensile reinforcement in both the experiment and FE analysis. The capacity and the failure mode observed in the FE analysis of Corroded Beam 113 with $v_{r s}=2.0$ agree well with the experiment; however, when a larger value was assumed for the volumetric expansion of oxides, $v_{r s}=$ 3.4 , the beam failed due to crushing of concrete owing to very low compressive strength. This led to underestimation of the capacity of the beam. From the experimental loaddisplacement curve of this beam, it can be imagined that one tensile reinforcement bar failed in bending first, perhaps due to a higher level of corrosion, and the capacity of the beam was reduced to almost half; then, the other reinforcement failed. In the FE analysis of Corroded Beam 113, however, both tensile reinforcements were assumed to reach the yield capacity at the same time. The deformation at peak load depended on how large the $\alpha_{1}$ coefficient was chosen. The results of FE analyses with different $\alpha_{1}$ coefficients - that is, 0.015, 0.017, and 0.021-are shown in Fig. 7(a).

The FE analysis of Noncorroded Beam 132 showed that the beam failed in shear shortly after the anchorage capacity was reached, which agrees very well with the experiment (refer to Fig. 6(b)). The analysis showed that the anchorage failure occurred in the region where half of the tensile reinforcement was curtailed-that is, $250 \mathrm{~mm}$ (9.75 in.) from the end of the beam. The change of failure mode from combined shear and anchorage failure to shear failure was observed in the experiment and FE analysis of Corroded Beam 135. Although the corrosion affected the anchorage capacity of the corroded beam, the severe corrosion of stirrups reduced the shear capacity of the beam to a larger extent.

Different combinations of uniform and pitting corrosion for Corroded Beam 135 were examined and the results are shown in Fig. 7(b). In the analysis when pitting corrosion alone was introduced to all critical reinforcement sections, the capacity of the beam was underestimated, seeing as though only $60 \%$ of the capacity was observed in the experiment. Considering only uniform corrosion overestimated the capacity, indicating that the notch effect caused by pitting corrosion may limit the ductility and capacity of the beam to some extent, which is not negligible. The result of the analysis, which considered both uniform corrosion and pitting corrosion randomly distributed over the stirrups and reinforcement, showed a better agreement with the experiment.

\section{Analytical method}

The bending and shear capacity of the beams were estimated using Eurocode $2,{ }^{37}$ where the material properties of concrete and corroded reinforcement were chosen on the basis of the proposed methodology. It is obvious that in a real structure, the observation of the actual deteriorated cross section should be used in analytical calculations of the capacity. Because this type of observation has not been reported ${ }^{1}$ for the studied beams, however, several different assumptions for the residual cross section were made.

The bending and shear capacity were calculated for six different cross sections, including one noncorroded cross section (Table 3). The effects of uniform and pitting corrosion 


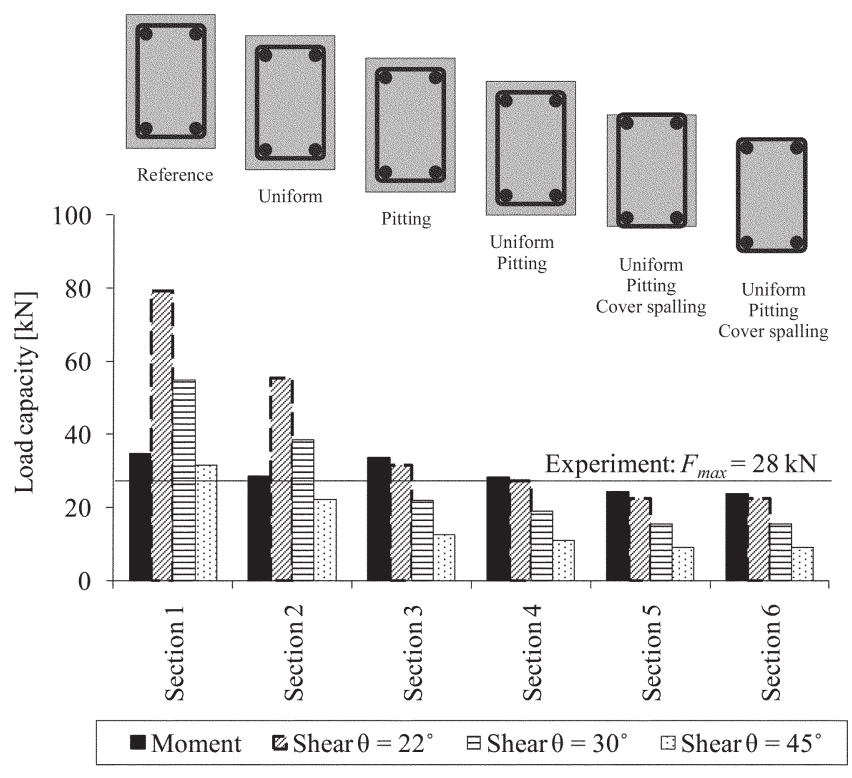

(a)

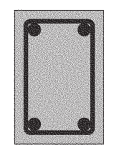

Reference

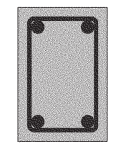

Uniform

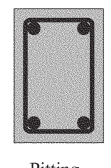

Pitting
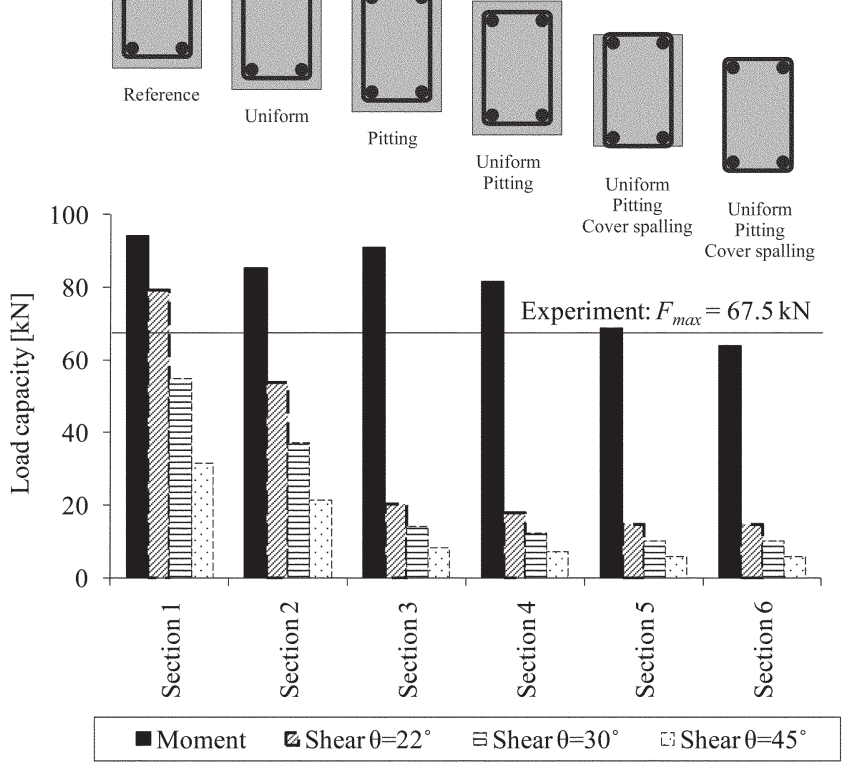

(b)

$1 \mathrm{kN}=0.225$ kips.

Fig. 8-Moment and shear capacity: (a) Corroded Beam 113; and (b) Corroded Beam 135.

were first considered separately in Cross Sections 2 and 3 and then together in Cross Section 4. The calculation for Cross Section 5 predicts the capacity of the beam when pitting and uniform corrosion have caused spalling of the top and bottom cover. Cross Section 6 is the extreme case when the entire cover is disregarded. In the calculations, it was assumed that pitting corrosion affected the stirrups and the tensile reinforcement in critical regions - that is, for stirrups where shear cracks with an angle of $\theta=22,30$, and 45 degrees cross the stirrups and for tensile reinforcement where the maximum bending moment occurs. Note that to enable a comparison between the analytical results and experiments, no safety factors were used.

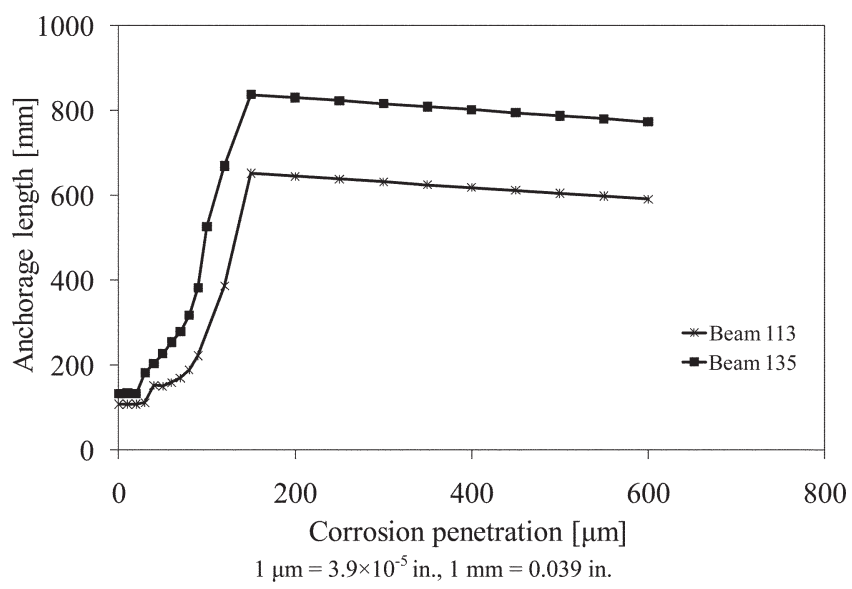

Fig. 9-Anchorage length needed to anchor yield force versus corrosion penetration.

\section{Results and discussion of analytical method}

The shear and moment capacities of Corroded Beams 113 and 135 calculated in accordance with Eurocode 237 for the six different cross sections are presented in Fig. 8. Comparing Cross Sections 1, 2, and 3, it can be seen that uniform and pitting corrosion affected the shear capacity of both corroded beams to a large extent. This is due to highly corroded stirrups compared to moderately corroded tensile and compressive reinforcement. Cross Section 4 is expected to show a better agreement with the experiments, as both uniform and pitting corrosion but no cover spalling has been reported. For Corroded Beam 113, the expected load capacity for the bending failure of Cross Section 4 corresponded to the measured one fairly well. Actually, for Cross Section 4 of Corroded Beam 113, analyses of bending and shear failures with an angle of 22 degrees resulted in almost the same load capacity, while the tested beam failed in bending. Thus, there appears to be a larger safety margin for shear failure than for bending failure in the code, which is as expected. The shear capacity of Corroded Beam 135 was estimated on the safe side by considering only uniform corrosion-Cross Section 2. Cross Sections 3 to 6 estimated much lower shear capacity for the beam, although all cross sections except Cross Section 1 predicted the correct failure mode- shear failure.

The anchorage length needed to anchor the yield force was calculated from the bond-slip behavior, as described in the literature ${ }^{30}$ (Fig. 9). It was assumed that the crosssectional area of the reinforcement bar decreased uniformly. The bond loss that occurs when the reinforcement yields was not included in these analyses. Thus, the calculated length will manage to anchor the yield force until yielding occurs; thereafter, a pullout failure will take place. The computed anchorage length showed a very large increase for Corroded Beam 113 from approximately $100 \mathrm{~mm}$ (3.9 in.) for zero corrosion penetration to $670 \mathrm{~mm}(26.13 \mathrm{in}$.) for $160 \mathrm{~mm}$ (0.0062 in.) corrosion penetration. However, it was still not limiting the total capacity of the beam, which failed in bending. The increase in the anchorage length for Corroded Beam 135 is very similar and the anchorage was not critical for the total capacity.

\section{CONCLUSIONS}

This paper has presented a methodology to analyze the mechanical behavior of corroded RC structures. It is 
proposed that the mechanical effects of corrosion can be modeled as a change in geometry and properties - that is, the reduction of steel area and ductility, removal of spalled concrete, modification of concrete response due to corrosion cracks, and modification of bond-slip properties.

The methodology was used in combination with nonlinear fracture mechanics in FE analysis and hand calculations. The results of the analyses were compared with available experimental results to verify the capability of the proposed method. Based on the results, the following conclusions can be drawn:

- The methodology is applicable to different approximation levels - for example, ranging from full 3-D solid models to the simplest engineering calculation.

- The load-carrying capacity and failure mode of the studied corroded beams were well estimated by the proposed methodology in combination with nonlinear FE analyses.

- When the methodology was used in analyses according to Eurocode 2, ${ }^{37}$ the estimated load capacities were on the safe side.

- Considering only uniform corrosion may lead to overestimation of the residual load-carrying capacity of the structure. For better estimation, both corrosion effects have to be taken into account.

- The main uncertainties were in the $\alpha_{1}$ coefficient, which represents the ductility reduction of the corroded reinforcing bar and the variability of pitting corrosion in terms of when and where it takes place.

- The comparison made with the tests from the literature is mainly useful to verify the proposed methodology for the given corrosion levels (up to $500 \mu \mathrm{m}$ [0.0195 in.] corrosion penetration). Therefore, further verification of the 1-D bond-slip model and the proposed methodology is needed for a higher amount of corrosion attack.

- Based on these conclusions, it is proposed to further investigate the ductility reduction with both pitting and uniform corrosion for different exposure conditions.

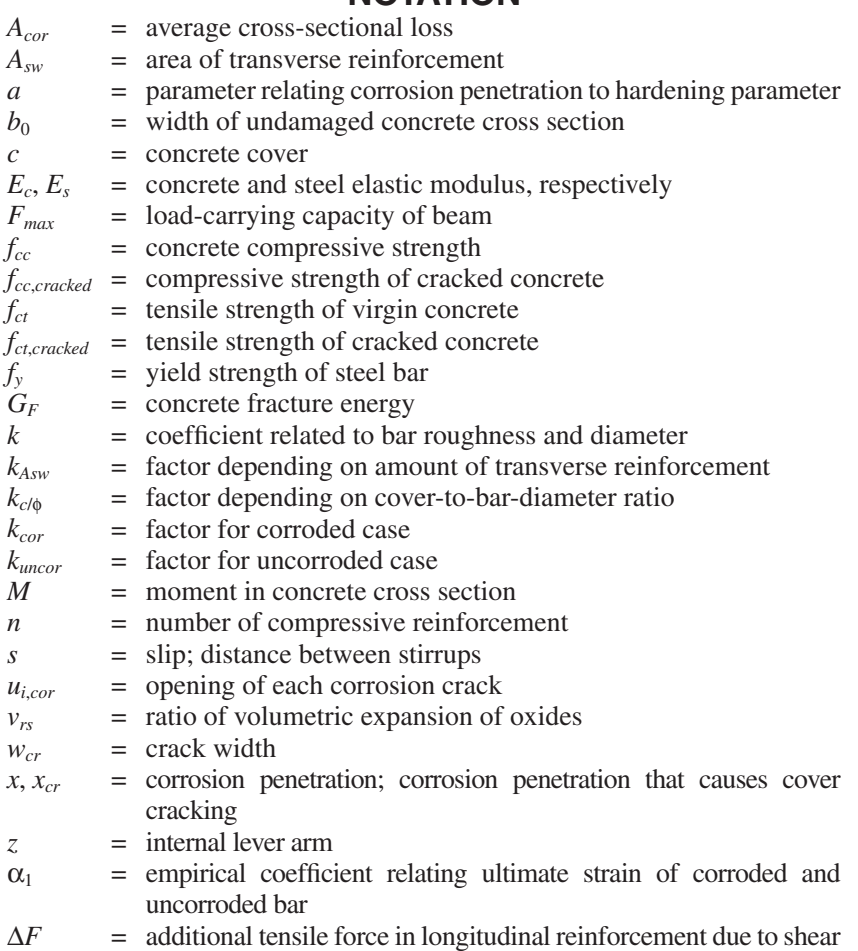

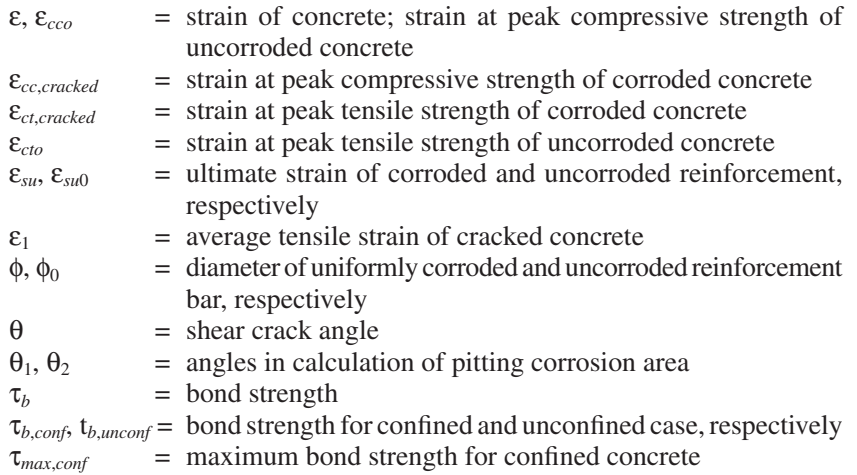

\section{REFERENCES}

1. Rodriguez, J.; Ortega, L. M.; and Casal, J., "Load Carrying Capacity of Concrete Structures with Corroded Reinforcement," Construction and Building Materials, V. 11, No. 4, 1997, pp. 239-248.

2. Huang, R., and Yang, C. C., "Condition Assessment of Reinforced Concrete Beams Relative to Reinforcement Corrosion," Cement and Concrete Composites, V. 19, No. 2, 1997, pp. 131-137.

3. International Federation for Structural Concrete (fib) Bulletin 10, "Bond of Reinforcement in Concrete, State-of-Art Report," Fédération Internationale du Béton, prepared by Task Group Bond Models, Lausanne, 2000, 434 pp.

4. Coronelli, D., and Gambarova, P., "Structural Assessment of Corroded Reinforced Concrete Beams: Modeling Guidelines," Journal of Structural Engineering, ASCE, V. 130, No. 8, 2004, pp. 1214-1224.

5. Cairns, J., and Millard, S., "Reinforcement Corrosion and its Effect on Residual Strength of Concrete Structures," Proceedings of the Eighth International Conference on Structure Faults and Repair, Edinburgh, UK, 1999.

6. Auyeung, Y.; Balaguru, P.; and Chung, L., "Bond Behavior of Corroded Reinforcement Bars," ACI Materials Journal, V. 97, No. 2, Mar.-Apr. 2000, pp. 214-220.

7. Almusallam, A. A.; Al-Gahtani, A. S.; and Aziz, A. R., "Effect of Reinforcement Corrosion on Bond Strength," Construction and Building Materials, V. 10, No. 2, 1996, pp. 123-129.

8. Lundgren, K., "Modelling the Splitting Effects of Corrosion in Reinforced Concrete," Computational Modelling of Concrete Structures, Euro-C Conference, St. Johann, Austria, 2003, pp. 491-500.

9. Almusallam, A. A. et al., "Effect of Reinforcement Corrosion on Flexural Behavior of Concrete Slabs," Journal of Materials in Civil Engineering, ASCE, V. 8, No. 3, 1996, pp. 123-127.

10. Azad, A. K.; Ahmad, S.; and Azher, S. A., "Residual Strength of Corrosion-Damaged Reinforced Concrete Beams," ACI Materials Journal, V. 104, No. 1, Jan.-Feb. 2007, pp. 40-47.

11. Zandi Hanjari, K., "Load-Carrying Capacity of Damaged Concrete Structures," licentiate thesis, Chalmers University of Technology, Gothenburg, Sweden, 2008, 98 pp

12. Lundgren, K., "Bond between Ribbed Bars and Concrete. Part 2: The Effect of Corrosion," Magazine of Concrete Research, V. 57, No. 7, 2005, pp. 383-395.

13. Schlune, H., "Bond of Corroded Reinforcement: Analytical Description of the Bond-Slip Response," MSc thesis, Chalmers University of Technology, Gothenburg, Sweden, 2006, 73 pp.

14. Lundgren, K. et al., "Effects on Bond of Reinforcement Corrosion," International RILEM Workshop on Integral Service Life Modeling of Concrete Structures, Guimarães, Portugal, November 5-6, 2007, pp. 231-238.

15. Vecchio, F. J., and Collins, M. P., "Compression Response of Cracked Reinforced Concrete," Journal of Structural Engineering, ASCE, V. 119, No. 12, 1993, 3590 pp.

16. Molina, F. J.; Alonso, C.; and Andrade, C., "Cover Cracking as a Function of Rebar Corrosion 2-Numerical Model," Materials and Structures, V. 26, No. 163, 1993, pp. 532-548.

17. Capé, M., "Residual Service-Life Assessment of Existing R/C Structures," MSc thesis, Chalmers University of Technology, Gothenburg, Sweden, and Milan University of Technology, Milan, Italy, 1999, 133 pp.

18. Pantazopoulou, S. J., and Papoulia, K. D., "Modeling Cover-Cracking due to Reinforcement Corrosion in RC Structures," Journal of Engineering Mechanics, ASCE, V. 127, No. 4, 2001, pp. 342-351.

19. Liu, Y., and Weyers, R. E., "Modeling the Time-to-Corrosion Cracking in Chloride Contaminated Reinforced Concrete Structures," ACI Materials Journal, V. 95, No. 6, Nov.-Dec. 1998, pp. 675-681.

20. Bhargava, K.; Ghosh, A. K.; Mori, Y.; and Ramanujam, S., "Model for Cover Cracking due to Rebar Corrosion in RC Structures," Engineering Structures, V. 28, No. 8, 2006, pp. 1093-1109. 
21. Du, Y. G.; Clark, L. A.; and Chan, A. H. C., "Effect of Corrosion on Ductility of Reinforcing Bars," Magazine of Concrete Research, V. 57, No. 7, 2005, pp. 407-419.

22. Almusallam, A. A., "Effect of Degree of Corrosion on the Properties of Reinforcing Steel Bars," Construction and Building Materials, V. 15, No. 8, 2001, pp. 361-368.

23. Cairns, J. et al., "Mechanical Properties of Corrosion-Damaged Reinforcement," ACI Materials Journal, V. 102, No. 4, July-Aug. 2005, pp. 256-264.

24. Du, Y., "Effect of Reinforcement Corrosion on Structural Concrete Ductility," PhD thesis, University of Birmingham, UK, 2001, 320 pp.

25. Gonzalez, J. A. et al., "Some Questions on the Corrosion of Steel in Concrete-Part I: When, How and How Much Steel Corrodes," Materials and Structures, V. 29, No. 185, 1996, pp. 40-46.

26. Val, D. V., and Melchers, R. E., "Reliability of Deteriorating RC Slab Bridges," Journal of Structural Engineering, ASCE, V. 123, No. 12, 1997, pp. 1638-1644.

27. Stewart, M. G., and Al-Harthy, A., "Pitting Corrosion and Structural Reliability of Corroding RC Structures: Experimental Data and Probabilistic Analysis," Reliability Engineering and System Safety, V. 93, No. 3, 2008, pp. 373-382.

28. Palsson, R., and Mirza, M. S., "Mechanical Response of Corroded Steel Reinforcement of Abandoned Concrete Bridge," ACI Structural Journal, V. 99, No. 2, Mar.-Apr. 2002, pp. 157-162.

29. Darmawan, M. S., and Stewart, M. G., "Effect of Pitting Corrosion on Capacity of Prestressing Wires," Magazine of Concrete Research, V. 59, No. 2, 2007, pp. 131-139.
30. Lundgren, K.; Kettil, P.; Zandi Hanjari, K.; Schlune, H.; and San Roman, A. S., "Analytical Model for the Bond-Slip Behaviour of Corroded Ribbed Reinforcement," Structure and Infrastructure Engineering, first published on Dec. 21, 2009, (iFirst), http://dx.doi. org/10.1080/15732470903446993.

31. CEB-FIP, “CEB-FIP Model Code 1990,” Bulletin d'Information 213/214, Lausanne, Switzerland, 1993, 437 pp.

32. Coronelli, D., "Bar Corrosion in Steel-Concrete Bond: Material and Structural Effects in R/C," PhD thesis, Politecnico di Milano, Milan, Italy, 1998, 201 pp.

33. DIANA, "DIANA Finite Element Analysis, User's Manual," Release 9.1., TNO Building and Construction Research, Delft, the Netherlands.

34. Hordijk, D. A.; Cornelissen, H. A. W.; and Reinhardt, H. W., "Experimental Determination of Crack Softening Characteristics of Normalweight and Lightweight Concrete," Heron, V. 31, No. 2, 1986, pp. $45-56$.

35. Thorenfeldt, E.; Tomaszewicz, A.; and Jensen, J. J., "Mechanical Properties of High-Strength Concrete and Applications in Design," Conference on Utilization of High-Strength Concrete, Stavanger, Norway, 1987, pp. 149-159.

36. Van Mier, J. G. M., "Strain-Softening of Concrete under Multiaxial Loading Conditions," PhD thesis, Eindhoven, the Netherlands, 1984, 349 pp.

37. Eurocode 2, "Design of Concrete Structures. Part 1-1: General Rules and Rules for Building (ENV1992-1-1)," 1992, 225 pp. 